\section{Dengue Fever in the Darfur Area, Western Sudan}

\section{Ayman Ahmed, Yousif Ali, Babiker Elmagboul, Omaima Mohamed, Adel Elduma, Hind Bashab, Ahmed Mahamoud, Hayat Khogali, Arwa Elaagip, Tarig Higazi}

\author{
Author affiliations: Liverpool School of Tropical Medicine, \\ Liverpool, UK (A. Ahmed); University of Khartoum, Khartoum, \\ Sudan (A. Ahmed, A. Elaagip); Sudan Federal Ministry of \\ Health, Khartoum (Y. Ali, B. Elmagboul, O. Mohamed, A. Elduma, \\ H. Bashab, A. Mahamoud, H. Khogali); Ohio University, \\ Zanesville, Ohio, USA (T. Higazi)
}

DOI: https://doi.org/10.3201/eid2511.181766

We report an outbreak of dengue in Darfur, western Sudan, during September 2014-April 2015. Dengue virus-specific PCR testing of 50 samples from nonmalaria febrile illness case-patients confirmed 35 dengue cases. We detected 7 cases of dengue shock syndrome and 24 cases of dengue hemorrhagic fever.

$\mathrm{D}$ engue is a mosquito-transmitted arboviral disease caused by 4 closely related dengue virus serotypes (DENV1-4); the primary vector of DENV is Aedes aegyp$t i$ mosquitoes (1). Dengue infection has different clinical manifestations of disease, ranging from a self-limiting illness to the fatal severe forms of dengue hemorrhagic fever or dengue shock syndrome (1).

Dengue is a rapidly growing global public health problem, and cases have been identified in $\geq 128$ countries $(2,3)$. Several factors might contribute to dengue transmission, including human population growth, density, and movement, and international travel and trade $(4,5)$, as well as scarcity and poor storage of water and global climate change. Secondary infection with different virus serotypes and sex and young age of patients seem to be associated with development of severe disease (1).
The Darfur region of Sudan is composed of 5 states covering an area of $493,180 \mathrm{~km}^{2}$ of desert and semidesert. This region has a population of 7.5 million persons living in a humanitarian crisis since 2003. We report dengue fever in this region of western Sudan.

On September 16, 2014, a large number of case-patients with nonmalarial febrile illness came to outpatient clinics in AlFashir, the capital of North Darfur State. An outbreak investigation team was assembled and deployed to the area by the Federal Ministry of Health. Using active surveillance, this team identified 155 suspected cases of hemorrhagic fever in various localities within the state through April 12, 2015. The suspected case-patients had fever (152/155), bleeding (140/155), headache (73/155), joint pain (52/155), and neurologic signs (9/155). Most case-patients came from AlFashir, the initial location of the outbreak. The outbreak peaked during October 2014 with $77(49.7 \%)$ suspected cases (Figure). Most (52\%) of the suspected case-patients were $<20$ years of age $(52 \%)$ (age range 18 months-74 years), and the female:male ratio was 1:1.5.

Clinical manifestations of the suspected case-patients suggested involvement of hemorrhagic fevers. Considering the history of similar epidemics of fevers in Sudan and our limited resources, we tested samples for yellow fever virus, Rift Valley fever virus, and DENV (6,7). We tested blood samples from suspected case-patients for these infections by using IgM-specific ELISAs, and all positive results were confirmed by use of a disease-specific PCR in the Central National Public Health Laboratory in Khartoum (7).

We obtained only 50 blood samples from 155 suspected case-patients because of patient or family refusal to participate in this study. A total of 35 (70.0\%) samples were positive for DENV-1 or DENV-3 serotypes. Eight deaths occurred among the DENV-positive persons (mortality rate $5.2 \%$ ) during the investigation period. Four of the fatal cases were in children $<14$ years of age, 2 in adult men, and 2 in adult women. Clinical examination of the confirmed infected persons identified 7 cases of dengue shock syndrome and 24 cases of dengue hemorrhagic fever.

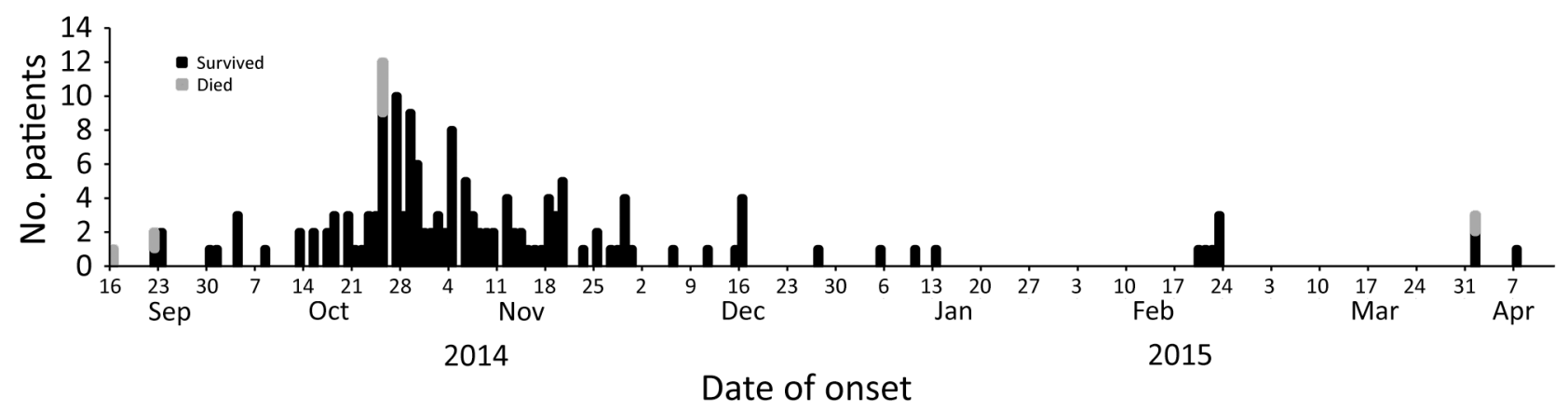

Figure. Number of dengue case-patients per week, Darfur area, western Sudan, September 16, 2014-April 7, 2015. 
We report emergence of dengue in the Greater Darfur area of Sudan. Dengue is a major public health issue in this country, but had been confined to the eastern region of the country and the Red Sea coastal and subcoastal states (4). Frequent outbreaks have been reported to the World Health Organization Regional Office for the Eastern Mediterranean (6). Greater Darfur, a region affected by a civil war, has had massive population displacement, resulting in most persons living in densely populated refugee camps with limited access to education and health services. Lack of water supply necessitated its storage in human-made containers (8), which favored breeding of Ae. aegypti mosquitoes and increased human-mosquito contact.

The severity of these infections could be because our surveillance selected only the most severe cases, enhanced by the poor healthcare-seeking behavior of the local population, who came to health clinics only when the disease was severe (7). The actual prevalence of dengue could be much higher than that detected because our surveillance system likely detected only the most severe cases (7). A wider and better surveillance system is urgently needed to detect nonsevere cases and determine the actual prevalence of the disease and population at risk.

In addition, Gayer et al. suggested that socioeconomic and environmental changes associated with the civil war in Sudan made communities vulnerable to the emergence of infectious diseases (8). The geopolitical and security issues surrounding the refugee camps suggest that dengue was imported into the area through members of United Nations Peacekeeping Forces from dengue-endemic areas rather than being introduced from East Sudan, as has been observed in Australia (8-10).

Our study had some limitations. First, we observed weak healthcare-seeking behavior, which resulted in insufficient blood samples for diagnosis. Second, because of limited resources, we could not investigate co-infections with DENV-1 and DENV-3. Third, our survey was conducted in healthcare clinics where only severe case-patients were seen. We recommend improvement of surveillance and development of an early warning system to reduce future impacts of such epidemics. We also highlight the need to improve health and living conditions of persons living in humanitarian crisis settings.

\section{Acknowledgments}

We thank our colleagues at the National Public Health Laboratory, Ministry of Health, Darfur State, Sudan, and the
Institut Pasteur de Dakar, Dakar, Senegal, for providing support and help with laboratory tests and molecular confirmation of circulating dengue virus serotypes.

\section{About the Author}

Mr. Ahmed is a research fellow at the Institute of Endemic Diseases, University of Khartoum, Khartoum, Sudan, and a Wellcome Trust Master Fellow of Public Health and Tropical Medicine at Liverpool School of Tropical Medicine, Liverpool, UK. His research interests are control of arboviral diseases and hemorrhagic fevers.

\section{References}

1. Simmons CP, Farrar JJ, Nguyen V, Wills B. Dengue. N Engl J Med. 2012;366:1423-32. https://doi.org/10.1056/NEJMra1110265

2. Bhatt S, Gething PW, Brady OJ, Messina JP, Farlow AW, Moyes $\mathrm{CL}$, et al. The global distribution and burden of dengue. Nature. 2013;496:504-7. https://doi.org/10.1038/nature12060

3. Brady OJ, Gething PW, Bhatt S, Messina JP, Brownstein JS, Hoen AG, et al. Refining the global spatial limits of dengue virus transmission by evidence-based consensus. PLoS Negl Trop Dis. 2012;6:e1760. https://doi.org/10.1371/journal.pntd.0001760

4. Soghaier MA, Himatt S, Osman KE, Okoued SI, Seidahmed $\mathrm{OE}$, Beatty ME, et al. Cross-sectional community-based study of the socio-demographic factors associated with the prevalence of dengue in the eastern part of Sudan in 2011. BMC Public Health. 2015;15:558. https://doi.org/10.1186/s12889-015-1913-0

5. Wilder-Smith A, Gubler DJ. Geographic expansion of dengue: the impact of international travel. Med Clin North Am. 2008;92: 1377-90, x. https://doi.org/10.1016/j.mcna.2008.07.002

6. Endy TP, Anderson KB, Nisalak A, Yoon I-K, Green S, Rothman AL, et al. Determinants of inapparent and symptomatic dengue infection in a prospective study of primary school children in Kamphaeng Phet, Thailand. PLoS Negl Trop Dis. 2011;5:e975. https://doi.org/10.1371/journal.pntd.0000975

7. Ahmed A, Elduma A, Magboul B, Higazi T, Ali Y. The first outbreak of dengue fever in greater Darfur, Western Sudan. Trop Med Infect Dis. 2019;4:43. https://doi.org/10.3390/tropicalmed4010043

8. Gayer M, Legros D, Formenty P, Connolly MA. Conflict and emerging infectious diseases. Emerg Infect Dis. 2007;13:1625-31. https://doi.org/10.3201/eid1311.061093

9. Duong V, Lambrechts L, Paul RE, Ly S, Lay RS, Long KC, et al. Asymptomatic humans transmit dengue virus to mosquitoes. Proc Natl Acad Sci U S A. 2015;112:14688-93. https://doi.org/10.1073/ pnas. 1508114112

10. Kitchener S, Leggat PA, Brennan L, McCall B. Importation of dengue by soldiers returning from East Timor to north Queensland, Australia. J Travel Med. 2002;9:180-3. https://doi.org/ $10.2310 / 7060.2002 .24234$

Address for correspondence: Ayman Ahmed, University of Khartoum, PO Box 2318, Khartoum 11111, Sudan; email: ayman.ame.ahmed@gmail.com 